\title{
Ventricular Tachycardia by ECG Finding
}

National Cancer Institute

\section{Source}

National Cancer Institute. Ventricular Tachycardia by ECG Finding. NCI Thesaurus. Code C111103.

An electrocardiographic finding of three or more consecutive complexes of ventricular organ with a rate greater than a certain threshold (100 or 120 beats per minute are commonly used). The QRS complexes are wide and have an abnormal morphology. (CDISC) 